\title{
Picosecond spectroscopy of the isolated reaction centers from the photosystems of oxygenic photosynthesis-ten years (1987-1997) of fun
}

\author{
A tribute to Michael R. Wasielewski on his 60th birthday
}

\author{
Govindjee $\cdot$ Michael Seibert
}

Received: 2 October 2009/ Accepted: 24 October 2009/Published online: 19 November 2009

(C) Springer Science+Business Media B.V. 2009

\begin{abstract}
Mike Wasielewski's pioneering work on Photosystem II photochemistry has an important place in the history of photosynthesis; we are proud to have been associated with him in making those first measurements. Here, we present our association and publications with him, and provide some of the history behind this research.
\end{abstract}

Keywords Ultrafast measurements · Photosystem II · Reaction center - Charge separation - Radical pair states . History of photosynthesis

\section{Early work with Mike Wasielewski was on photosystem I in 1987}

Both the authors (Govindjee (G) and Michael Seibert (MS)) had been interested in ultrafast/very fast primary events of oxygenic photosynthesis before our collaborations with Mike Wasielewski began (see e.g., Merkelo et al. 1969; Seibert et al. 1973). The interest of one of us $(\mathrm{G})$ in primary charge separation kinetics in the photosystems of oxygenic photosynthesis began in the late 1970s. $\mathrm{G}$ had a graduate student in Biophysics, James (Jim)

Govindjee $(\bowtie)$

Departments of Biochemistry and Plant Biology and the Center of Biophysics \& Computational Biology, University of Illinois at Urbana-Champaign, 265 Morrill Hall, 505 South Goodwin Avenue, Urbana, IL 61801, USA

e-mail: gov@life.illinois.edu

M. Seibert

13134 W. Yale Place, Lakewood, CO 80228, USA
Fenton, who started constructing a picosecond transient absorption spectrometer in his laboratory in Morrill Hall at the University of Illinois at Urbana-Champaign (UIUC). Jim and G began measurements on Photosystem I (PSI) reaction center (RC) particles from spinach, and were beginning to obtain some preliminary data. During this period, Kenneth J. Kaufmann was hired as an Assistant Professor of Chemistry at UIUC, and he started building a much more sophisticated and sensitive instrument. Hence, $\mathrm{G}$ joined forces with him, and Jim began obtaining meaningful data on the instrument in the Noyes laboratory with Michael J. Pellin in Ken's laboratory. Mike Pellin obtained his $\mathrm{PhD}$ in 1978 at the UIUC, and, then went to the Argonne National Laboratory, where he is now the Director of the Materials Science Division. Their first paper on picosecond charge separation time was published in 1979 (Fenton et al. 1979). Jim collected tremendous amounts of data, but none of that was published as he wanted to fully understand the system. Sometime during this period Ken Kaufmann left the UIUC to join Hamamatsu Photonics on the East Coast. G does not remember the date or the details as to how he discovered the outstanding work and the laboratory of Michael (Mike) R. Wasielewski (MW) at the Argonne National laboratory, but they began to discuss possible experiments at the Photosynthesis Gordon Research Conference in 1983 in California. G took PSI RC samples to MW's laboratory at Argonne in 1985, and these newer experiments led to the publication of a more definitive paper on the primary charge separation rate in the picosecond time scale (Wasielewski et al. 1987) almost 8 years after the first paper from the UIUC. A link was thus established between the $\mathrm{G}$ and MW groups. Figure 1 shows a 1999 photograph of James Fenton, Govindjee, and Michael Wasielewski at Urbana, Illinois. 


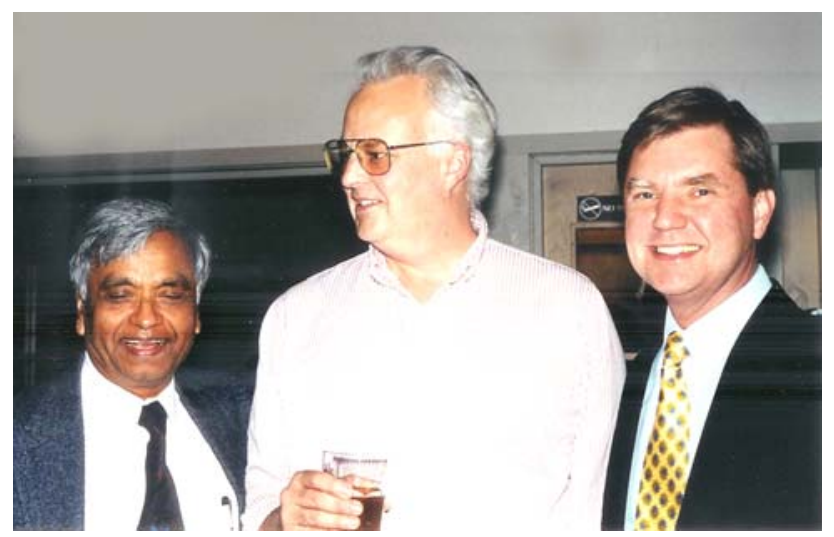

Fig. 1 A photograph (left to right) of Govindjee, Jim Fenton and Mike Wasielewski, the early Photosystem I team. Photo taken in 1999 at the time of the retirement symposium for Govindjee, held at the University of Illinois at Urbana-Champaign. Photo by Amy Whitmarsh

\section{Photosystem II work began in 1988 and ended in 1999}

Much of G's and MS's research at the time was also focused on Photosystem II (PS II), the unique system of oxygenic photosynthesis, which oxidizes water to molecular oxygen. Its RC was called P680, and was estimated to have a very positive redox potential $(\sim 1.2 \mathrm{eV})$ (see Jursinic and Govindjee 1977). However, during the early to mid 1980s, the proteins that actually constituted the PS II RC were the subject of intense discussion (Seibert and Wasielewski 2003, 2005). This was resolved with the exciting announcement of Kimiyuki Satoh, at the VIIth International Photosynthesis Congress in Providence, Rhode Island (August 10-15, 1986), that he and his student (Osamu Nanba) had successfully isolated the PS II RC complex from spinach and that it contained both the D1 and D2 proteins, five chlorophylls (now known to be 6, 2 more than the isolated bacterial RC), and two pheophytins. Satoh was very gracious at the Congress and fully described details of the isolation procedure to anyone who asked. MS went back to Colorado after the meeting and spent many hours in a cold room trying to reproduce the results. With some effort, purified PS II RC complex came off the Toyopearl 650S column, exactly as Satoh had said. However, the red absorption peak of the material right off the column was at 676 and not $673 \mathrm{~nm}$ as Nanba and Satoh had reported in their landmark paper (Nanba and Satoh 1987). MS thought this result was curious and spent a lot of time trying to characterize the material spectrally. It became apparent that the RC complex, as originally isolated, exhibited rapid blue-shifting of the red peak in both its absorption and fluorescence spectra. The reason for this turned out to be the inherent instability of the complex, and the National Research Energy Laboratory (NREL) shipped a paper off to a leading fast-publishing journal to warn colleagues that the RC material was labile and lost primary photochemical activity very rapidly, if exposed to air under room light and temperature conditions. Unfortunately, despite the spectroscopic characterization of the material and its labile nature, the paper was rejected because it was categorized as a 'methods' paper. It was then submitted to Plant Physiology. Fortunately, Plant Physiology saw the results as being relevant for those who wanted to use the new RC material, and MS's paper was published (Seibert et al. 1988) after some delay. For this and a follow-up article (McTavish et al. 1989), Rafael Picorel spent a lot of time, during his postdoctoral fellowship at NREL, helping to develop the techniques that are now widely used to stabilize isolated spinach PS II RC materials for spectroscopy (i.e., substitution of dodecyl maltoside for Triton X-100 and the use of an enzymatic $\mathrm{O}_{2}$-scrubbing system to prevent photooxidative damage). Figure 2 shows a photograph of Michael Seibert, Govindjee and Kimiyuki Satoh.

Unbeknownst to the NREL group, $G$ was also isolating PS II RCs at the time. Another graduate student in Biophysics, Hyunsuk Shim, joined Govindjee and Peter Debrunner in Physics at the UIUC, where she started to isolate PS II RC preparations sometimes in early 1988. G would take these samples to MW's laboratory, and he, along with his associates, would measure picosecond absorption changes in the P680 absorption region. They were very disappointed that although they could see bleaching of chlorophyll $a$, they could not observe any changes that they could assign to charge separation in PSII. Govindjee was puzzled until he reviewed the above-mentioned paper by MS for 'Plant Physiology' (Seibert et al. 1988). Here, MS and his coworkers described a rather simple method to stabilize these preparations. G telephoned MS and suggested that he join him and MW in measuring primary charge separation in the stabilized PSII material. From then on MW, MS and G decided to collaborate on this project, and it was a most pleasant experience for all three of us as

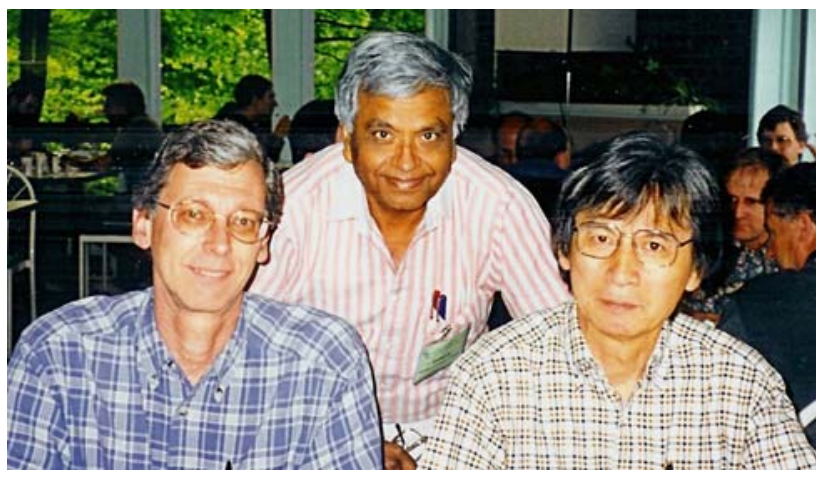

Fig. 2 A photograph (left to right) of Mike Seibert, Govindjee and Kimiyuki Satoh. Photo taken at one of the Gordon Conferences on Photosynthesis 


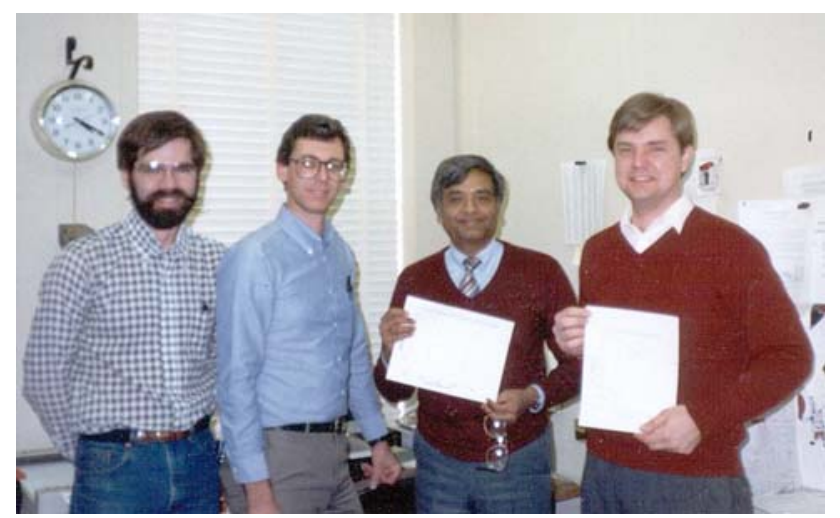

Fig. 3 A photograph (left to right) of Doug Johnson, Mike Seibert, Govindjee, and Mike Wasielewski at Argonne National Laboratory during the summer of 1988 with the results of the first direct measurements of primary charge-separation kinetics in isolated PSII reaction center complexes. Photo by Walter Svec

well as the several collaborators of the two Mikes. The first MW collaborator was Douglas G. Johnson (see Fig. 3). Our first paper was communicated by the late Joseph J. Katz (1912-2008) to the Proceedings of National Academy of Sciences, USA (see Wasielewski et al. 1989a). The time $(\tau)$ for the primary charge separation was $\sim 3$ ps! This was followed by a more detailed investigation on primary charge separation in the isolated PS II RC at $15 \mathrm{~K}$ (Wasielewski et al. 1989b) resulting in a slightly faster $1.4 \mathrm{ps}$ lifetime. At the time, we interpreted the events associated with primary charge separation as follows:

$\mathrm{P} 680 \mathrm{Pheo}_{\mathrm{D} 1} \stackrel{\mathrm{h} v}{\longrightarrow} \mathrm{P} 680^{*} \mathrm{Pheo}_{\mathrm{D} 1} \stackrel{3 \mathrm{ps}}{\longrightarrow} \mathrm{P} 680^{+} \mathrm{Pheo}_{\mathrm{D} 1}{ }^{-}$,

where P680 was a special pair containing 2 Chl, P680* the excited P680 singlet primary donor state, and Pheo was the primary acceptor. At the time, there was no PS II crystal structure, and we had no idea how the monomeric chlorophyll on the $\mathrm{D} 1$ side $\left(\mathrm{Chl}_{\mathrm{D} 1}\right)$ of the $\mathrm{RC}$ (by analogy to the bacterial RC) might be involved. Speculation at the time was that $\mathrm{Chl}_{\mathrm{D} 1}$ might be an intermediary on the path to $\mathrm{Pheo}^{-}$. Govindjee and Wasielewski (1989) presented a well received overview of "Photosystem II" at the 80th birthday of C. Stacy French. Initial confirmation of the work came when Jankowiak et al. (1989) measured the primary electron transfer rate using transient hole burning spectroscopy, and these data were in good agreement with our's obtained by time-resolved spectroscopy.

Additional experiments were done over the next couple of years with Doug and a new MW postdoc, Michael P. O'Neil. We presented our data and interpretations at two international meetings (Wasielewski et al. 1990, International Photosynthesis Congress, in Stockholm, Sweden, 1989; Seibert et al. 1992, International Photosynthesis Congress, Nagoya, Japan, 1992). Comments poured in from various sources over that period of time, one from the laboratory of the Nobel laureate Sir George Porter, Imperial College, London, UK, contending that the charge separation time was $\sim 21$ ps, not 3 ps (Durrant et al. 1992; Hastings et al. 1992). We dealt with these quite well although it was tough at times; however, others besides our group reported hole burning, fluorescence, and absorption recovery results consistent with a 3-ps lifetime and a longer time for energy transfer (Tang et al. 1991; Roelofs et al. 1991; Schelvis et al. 1994). MW was always very cool during this period, though there was one heated discussion that we all remember in Nagoya.

David (Dave) Gosztola joined Wasielewski's laboratory as a postdoc in 1992, just about the same time that Gary Wiederrecht did (see below). Dave was a key individual in setting up the Ti:sapphire laser system. (Figure 4 shows Dave's photograph with our team.) Dave is currently working as a staff scientist, on ultrafast laser techniques, in the Center for Nanoscale Materials at the Argonne National laboratory.

Subsequently, we remeasured the kinetics in spinach PSII RCs using femtosecond photodichroism techniques at the magic angle (pump and probe beams polarized at $54.7^{\circ}$ relative to one another, where no photoselection occurs) with Gary P. Wiederrecht in MW's lab (Wiederrecht et al. 1994) and got results similar to our earlier studies. The 3-ps component disappeared when Pheo was reduced prior to P680 excitation, giving us more confidence in our interpretation. Then, Scott Greenfield joined MW's laboratory. $\mathrm{He}$ carefully examined the wavelength and intensity dependency as well as effective rate constants for charge separation at $5^{\circ} \mathrm{C}(8 \mathrm{ps})^{-1}$ and $7 \mathrm{~K}(5 \mathrm{ps})^{-1}$ in isolated PS II $\mathrm{RCs}$, and also observed slower components interpreted as

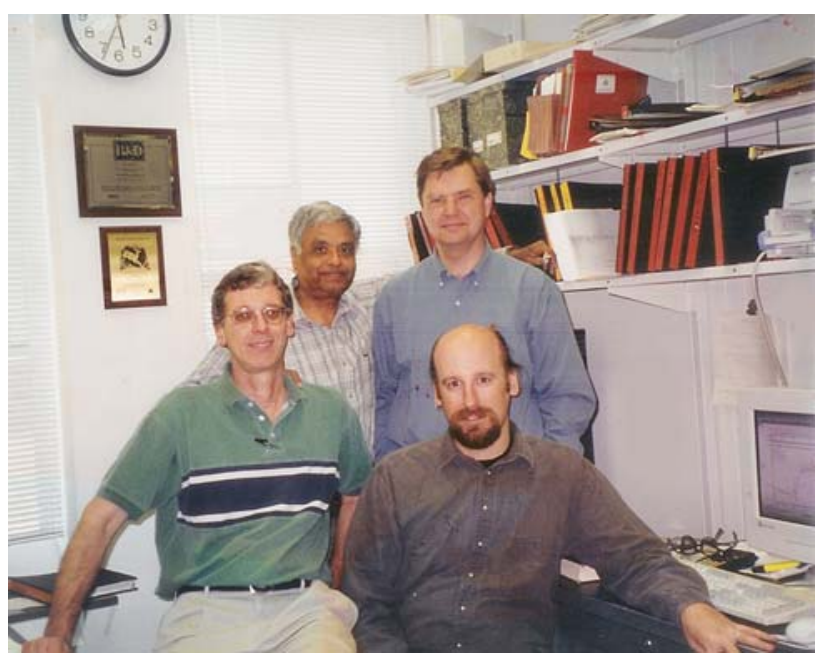

Fig. 4 A photograph of Dave Gosztola, taken in 1990s with our team. Front row (left to right): Michael Seibert and Dave Gosztola. Back row (left to right): Govindjee and Michael Wasielewski 


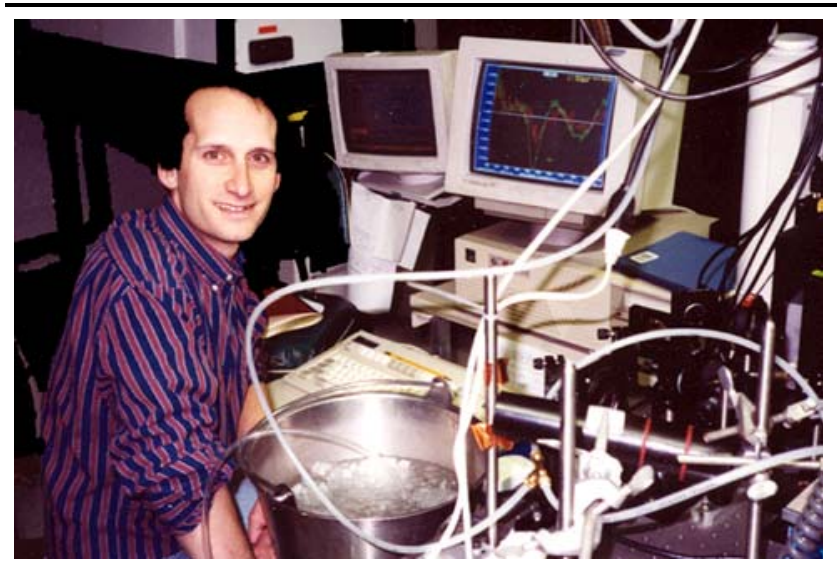

Fig. 5 A photograph of Scott Greenfield, taken in 1997, with Mike Wasielewski's first Ti-sapphire/OPA laser instrumentation, which he used to gather data after 1996. Photo by Govindjee

energy-transfer-limited charge transfer (Greenfield et al. 1995, presented at the International Congress in Photosynthesis at Montpelier, France; and Greenfield et al. 1996, 1997, 1999a, 1999b). The rates that Scott measured were a little slower than our earlier results, but they are consistent with current ideas summarized below. Figure 5 shows Scott Greenfield in front of MW's first Ti-sapphire/OPA laser system, which increased data collection capability to $200 \mathrm{~Hz}$ (limited by sample recovery time).

Figure 6 shows a picture taken on September 26, 2009, at the celebration dinner for Mike Wasielewski (Wazapalooza 2009, a 60th birthday Symposium in honor of Prof. Michael R. Wasielewski) in Evanston, Illinois, and includes G, MS, and MW, as well as Gary Wiederrecht and Mike Pellin mentioned above.

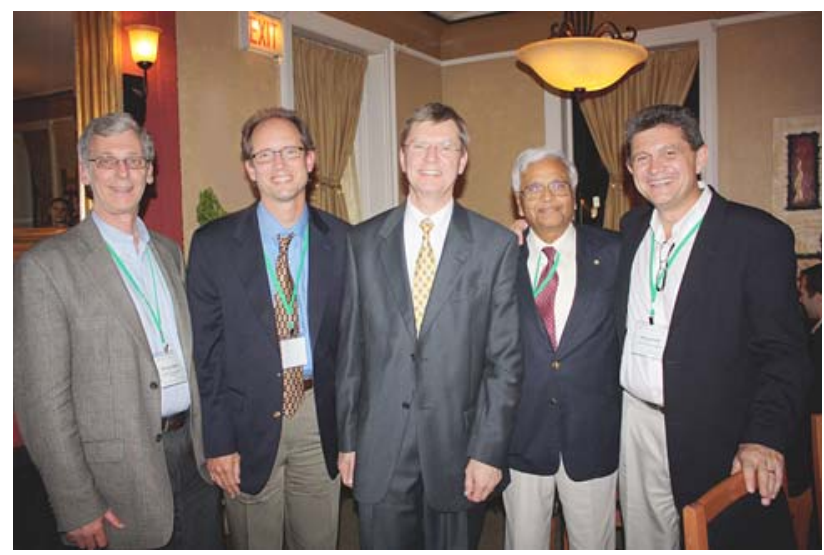

Fig. 6 A photograph (left to right) of Mike Seibert, Gary Wiederrecht, Mike Wasielewski, Govindjee, and Mike Pellin (mentioned above) at Mike Wasielewski's 60th birthday celebration (Wazapalooza 2009) at Northwestern University on September 26, 2009. See http://www.wazapalooza.org/. Photo by Nancy Wasielewski

\section{Beyond 1999}

When Govindjee retired in 1999, MW came to his retirement party. Thereafter the work continued on into the new millennium at Northwestern University with new collaborators (especially Dick Sayre at Ohio State University), a new organism (Chlamydomonas reinhardtii rather than spinach as examined above), and a new emphasis on PS II RC mutants (Wang et al. 2002; Xiong et al. 2004).

\section{Concluding remarks}

We now know that there are different processes going on, and that our $5^{\circ} \mathrm{C}$ numbers $(\tau=3-8 \mathrm{ps})$ describe some of the earliest primary events dominated by electron transfer, whereas the slower times ( $\tau=20-50 \mathrm{ps)}$ largely monitor energy transfer from the peripheral chlorophylls to the RC chlorophylls. The current interpretation of the faster events is as follows:

$$
\begin{gathered}
\mathrm{P}_{\mathrm{D} 1} \mathrm{Chl}_{\mathrm{D} 1} \mathrm{Pheo}_{\mathrm{D} 1} \stackrel{\mathrm{h} v}{\longrightarrow} \mathrm{P}_{\mathrm{D} 1} \mathrm{Chl}_{\mathrm{D} 1}{ }^{*} \mathrm{Pheo}_{\mathrm{D} 1} \stackrel{3 \mathrm{ps}}{\longrightarrow} \mathrm{P}_{\mathrm{D} 1} \mathrm{Chl}_{\mathrm{D} 1}{ }^{+} \\
\text {Pheo }_{\mathrm{D} 1} \stackrel{-5-8 \mathrm{ps}}{\longrightarrow} \mathrm{P}_{\mathrm{D} 1}{ }^{+} \mathrm{Chl}_{\mathrm{D} 1} \mathrm{Pheo}_{\mathrm{D} 1}{ }^{-},
\end{gathered}
$$

where $\mathrm{P}_{\mathrm{D} 1}$ is one of the two 'special pair' $\mathrm{P} 680$ Chls (the one on the D1 protein side). The difference between the earlier interpretation and the current thought is essentially the order in which the early events occur. It is highly likely then that what Sir George Porter's group, measured in London, was the total time, including excitation energy migration among the ensemble of ancillary Chls in the RC preparations. We had proposed sharing RC preparations between our two groups at the time, but that unfortunately never happened. New research (from Van Grondelle's group; see Groot et al. 2005) indicates that the first charge separation event occurring between $\mathrm{Chl}_{\mathrm{D} 1}$ and $\mathrm{Pheo}_{\mathrm{D} 1}$ may be very fast $(<1 \mathrm{ps})$. However, on the basis of their experiments, Holzwarth et al. (2006) considered 3 ps to be the value for this event. This is followed by secondary positive charge transfer from to $\mathrm{Chl}_{\mathrm{D} 1}$ to $\mathrm{P}_{\mathrm{D} 1}$, which in all likelihood, takes place within 3-8 ps. Detailed interpretations are still quite complex and open to debate (see a review by Renger and Holzwarth 2005). However, we note that Riley et al. (2004) provided evidence for highly dispersive primary charge separation kinetics and gross heterogeneity in isolated PS II RCs that were in agreement with Alfred Holzwarth's data. Novoderezhkin et al. (2007) have proposed that there may be mixing of exciton and chargetransfer states in PS II RCs. Probably there is not 'one' charge separation time/process in PS II, but several depending (particularly at low temperature) on the amount 
of inhomogeneous broadening. Furthermore, the rates of these processes may depend upon excitation wavelength, and this also complicates interpretation. Precise resolution of the events occurring in femtoseconds to picoseconds certainly requires additional measurements with PS II in vivo, not just in isolated RCs, as well as new theory.

We certainly had great fun doing the experiments described above. MS would bring the samples from Golden, CO; G would drive up to Argonne National Lab and handle the samples with MS; and MW with his associates would be ready for us with their instruments all set to go. We would have lunch together at the Argonne Cafeteria or an outstanding local 'dive' that served amongst the world's best burritos. We would also go out for dinner together at a nearby Japanese restaurant (Yokohama), where sushi and shashimi would end a long day in the lab! $\mathrm{G}$ also remembers using a long table outside the Lab to lie down and rest during late night runs. MS remembers the power outages, air conditioning problems, and the sudden inconvenient appearance of the 'Tiger Team' of US Department of Energy (DOE) at the door of MW's laser lab. (In 1991, such teams were known to perform intense and detailed safety inspection of all the DOE laboratories.) Nevertheless, we surmounted these problems, though they were sources of some frustration at the time, wrote papers together, exchanged drafts, and answered reviewers' comments. The most important part of this collaboration was the friendship we developed then and continue to cherish until today.

Michael Wasielewski's pioneering work on the measurement of Photosystem II primary photochemistry has an important place in the history of photosynthesis, and we are proud to have been associated with him in those first measurements.

Both Rienk Van Grondelle and Alfred Holzwarth have communicated to us their best wishes to MW on the occasion of his 60th birthday. Rienk writes: Mike is "a great guy and a great scientist". Unfortunately, neither Alfred nor Rienk could attend the celebration.

Acknowledgments We thank Alfred Holzwarth, Rienk Van Grondelle, and Ryszard Jankowiak for reading this manuscript and making valuable suggestions to improve it. We are indebted to the Wazapalooza team (Sarah Mickley, Vickie Gunderson, Annie Butler Rick, and Dick Co, MW's current graduate students, and postdocs who planned and executed the 60th birthday event at Northwestern University) for including us in this Great Event.

\section{References}

Durrant JR, Hastings G, Joseph DM, Barber J, Porter G, Klug DR (1992) Subpicosecond equilibration of excitation energy in isolated Photosystem II reaction centers. Proc Natl Acad Sci USA 89:11632-11636
Fenton JM, Pellin MJ, Kaufmann K, Govindjee (1979) Primary photochemistry of the reaction center of Photosystem I. FEBS Lett 100:1-4

Govindjee, Wasielewski MR (1989) Photosystem II: from a femtosecond to a millisecond. In: Briggs GE (ed) Photosynthesis. Alan Liss Publishers, NY, pp 71-103

Greenfield SR, Wasielewski M, Seibert M, Govindjee (1995) Femtosecond spectroscopy of PSII reaction centers: new results. In: Mathis P (ed) Photosynthesis: from light to biosphere, vol I. Kluwer Academic Publishers, Dordrecht, pp 663-666

Greenfield SR, Seibert M, Govindjee, Wasielewski MR (1996) Wavelength and intensity dependent primary photochemistry of isolated Photosystem II reaction centers at 5 C. Chem Phys 210:279-295

Greenfield SR, Seibert M, Govindjee, Wasielewski MR (1997) Direct measurement of the effective rate constant for primary charge separation in isolated Photosystem II reaction centers. J Phys Chem B 101:2251-2255

Greenfield SR, Seibert M, Wasielewski MR (1999a) Time-resolved absorption changes of the pheophytin $\mathrm{Q}_{\mathrm{X}}$ band in isolated Photosystem II reaction centers at $7 \mathrm{~K}$ : energy transfer and charge separation. J Phys Chem B 103:8364-8374

Greenfield SR, Wasielewski MR, Seibert M (1999b) Femtosecond PSII reaction center studies at $77 \mathrm{~K}$. In: Garab G (ed) Photosynthesis: mechanisms, effects, vol II. Kluwer Academic Publishers, Dordrecht, pp 1029-1032

Groot ML, Pawlowicz NP, Van Wilderen LJGW, Breton J, Van Stokkum IHM, Van Grondelle R (2005) Initial electron donor and acceptor in isolated Photosystem II reaction center identified with femtosecond mid-IR spectroscopy. Proc Natl Acad Sci USA 102:13087-13092

Hastings G, Durrant JR, Barber J, Porter G, Klug DR (1992) Observation of pheophytin reduction in Photosystem two reaction centers using femtosecond transient absorption spectroscopy. Biochemistry 31:7638-7647

Holzwarth A, Mueller RMG, Reus M, Nowaczyk M, Sander J, Roegner M (2006) Kinetics and mechanism of electron transfer in intact Photosystem II and in the isolated reaction center: pheophytin is the primary electron acceptor. Proc Natl Acad Sci USA 103:6895-6900

Jankowiak R, Tang D, Small GJ, Seibert M (1989) Transient and persistent hole burning of the reaction center of Photosystem II. J Phys Chem 93:1649-1654

Jursinic P, Govindjee (1977) Temperature dependence of delayed light emission in the 6 to 340 microsecond range after a single flash in chloroplasts. Photochem Photobiol 26:617-628

McTavish H, Picorel R, Seibert M (1989) Stabilization of isolated PSII reaction center complex in the dark and in the light using polyethylene glycol and an oxygen-scrubbing system. Plant Physiol 89:452-456

Merkelo H, Hartman SR, Mar T, Singhal GS, Govindjee (1969) Mode-locked lasers: measurements of very fast radiative decay in fluorescent systems. Science 164:301-302

Nanba O, Satoh N (1987) Isolation of a Photosystem II reaction center consisting of D-1 and D-2 polypeptides and cytochrome $b-555$. Proc Natl Acad Sci USA 84:109-112

Novoderezhkin VI, Dekker JP, Van Grondelle R (2007) Mixing of exciton and charge-transfer states in Photosystem II reaction centers: modeling of stark spectra with modified Redfield theory. Biophys J 93:1293-1311

Renger G, Holzwarth AR (2005) Primary electron transfer. In: Wydrzynski TJ, Satoh K (eds) Photosystem II: the light-driven water: plastoquinone oxidoreductase. Advances in Photosynthesis and Respiration, vol 22. Springer, Dordrecht, pp 139-175

Riley K, Jankowiak R, Rätsep M, Small GJ, Zazubovich V (2004) Evidence for highly dispersive primary charge separation 
kinetics and gross heterogeneity in the isolated reaction centers of green plants. J Phys Chem B 108:10346-10356

Roelofs TA, Gilbert M, Shuvalov VA, Holzwarth AR (1991) Picosecond fluorescence kinetics of the $\mathrm{D}_{1}-\mathrm{D}_{2}$-cytb-559 Photosystem II reaction center complex. Energy transfer and primary charge separation process. Biochim Biophys Acta 1060:237-244

Schelvis JPM, Van Noort PI, Aartsma TJ, Van Gorkom HJ (1994) Energy transfer, charge separation and pigment arrangement in the reaction center of Photosystem II. Biochim Biophys Acta 1184:242-250

Seibert M, Wasielewski MR (2003) The isolated Photosystem II reaction center: first attempts to directly measure the kinetics of primary charge separation. Photosynth Res 76:263-268

Seibert M, Wasielewski MR (2005) The isolated Photosystem II reaction center: first attempts to directly measure the kinetics of primary charge separation. In: Govindjee, Beatty JT, Gest H, Allen JF (eds) Discoveries in photosynthesis. Advances in photosynthesis and respiration, vol 20, pp 269-274. Springer, Dordrecht

Seibert M, Alfano RR, Shapiro SL (1973) Picosecond fluorescent kinetics of in vivo chlorophyll. Biochim Biophys Acta 292:493-495

Seibert M, Picorel R, Rubin AB, Connolly JS (1988) Spectral, photophysical and stability properties of isolated Photosystem II reaction center. Plant Physiol 87:303-306

Seibert M, Toon S, Govindjee, O’Neil MP, Wasielewski MR (1992) Primary charge separation in isolated Photosystem II reaction centers. In: Murata N (ed) Research in photosynthesis, vol II. Kluwer Academic Publishers, Dordrecht, pp 41-44

Tang D, Jankowiak, Seibert M, Small JG (1991) Effects of detergent on the excited state structure and relaxation dynamics of the Photosystem II reaction center: a high resolution hole burning study. Photosynth Res 29:19-29
Wang J, Gosztola D, Ruffle SV, Hemann C, Seibert M, Wasielewski MR, Hille R, Gustafson TL, Sayre RT (2002) Characterization of photosytem II peripheral chlorophyll mutants of Chlamydomonas reinhardtii. Proc Natl Acad Sci USA 99:4091-4096

Wasielewski MR, Fenton JM, Govindjee (1987) The rate of formation of P700 $\left.\left[^{+}\right]-\mathrm{Ao}^{-}\right]$in Photosystem I particles from spinach as measured by picosecond transient absorption spectroscopy. Photosynth Res 12:181-190

Wasielewski MR, Johnson DG, Seibert M, Govindjee (1989a) Determination of the primary charge separation rate in isolated Photosystem II reaction centers with 500 femtosecond time resolution. Proc Natl Acad Sci USA 86:524-548

Wasielewski MR, Johnson DG, Govindjee, Preston C, Seibert M (1989b) Determination of the primary charge separation rate in Photosystem II reaction centers at $15 \mathrm{~K}$. Photosynth Res 22: 89-100

Wasielewski MR, Johnson DG, Govindjee, Preston C, Seibert M (1990) The primary charge-separation rate in isolated Photosystem II reaction center complex. In: Baltscheffsky M (ed) Current research in photosynthesis, vol I. Kluwer Academic Publishers, Dordrecht, pp 451-454

Wazapalooza (2009) A 60th birthday symposium in honor of Prof. Michael R. Wasielewski. Program and Abstracts. September 25-26, Northwestern University, Evanston, Illinois, USA; see Govindjee on pages 27-32; and M. Seibert on pages 54-55

Wiederrecht GP, Seibert M, Govindjee, Wasielewski MR (1994) Femtosecond dichroism studies of isolated Photosystem II reaction centers. Proc Natl Acad Sci USA 91:8999-9003

Xiong L, Seibert M, Gusev AV, Wasielewski MR, Hemann C, Hille CR, Sayre RT (2004) Substitution of a chlorophyll into the inactive branch pheophytin-binding site impairs charge separation in Photosystem II. J Phys Chem B 108:16904-16911 